\title{
STRATEGIC SENSITIVITY AND ORGANIZATIONAL COMPETITIVENESS OF DEPOSIT MONEY BANKS IN NIGERIA
}

\author{
Margaret Diete-Spiff \\ Department of Management \\ Niger Delta University, Wilberforce Island,Amassoma \\ Bayelsa State Nigeria \\ margaretspiff@gmail.com \\ Christine A. Nwuche (PhD) \\ Department of Management \\ University of Port Harcourt,Choba \\ Rivers State, Nigeria
}

\begin{abstract}
This paper was designed as an empirical investigation of the relationship between strategic sensitivity and organizational competitiveness of deposit money banks in Rivers State, Nigeria. The research design was the cross-sectional survey and data was generated from 221 managers and supervisors from 18 deposit money banks in Rivers State, using the questionnaire instrument. Reliability was established using the Cronbach alpha reliability test. The Spearman's rank order correlation was utilized in the test for the hypotheses of the study. Based on the results, all null hypotheses were rejected as the findings revealed that strategic sensitivity significantly enhances organizational competitiveness outcomes such as innovativeness, service quality and delivery reliability. It was concluded that strategic sensitivity based on its emphasis on learning and knowledge development, promotes and enhances outcomes of service quality, innovativeness and delivery reliability.
\end{abstract}

Keywords: Strategic sensitivity, organizational competitiveness, innovativeness, service quality, delivery reliability 


\section{Introduction}

The business environment today is such that imposes and pushes for change and competition. Organizations are forced to compete in order to survive. Beal (2000) observe that in competing, most organizations fail to link their plans and structures with the emerging features and dynamics of their own context. This observation is reiterated by Hitt, Ireland and Hoskisson (2016) who observed that one of the major reasons organizations fail, especially within the service sector, is their inability to anchor strategies on the underlying contextual values and expectations that have overtime crystallized into realities of the context. This according to Jain and Moreno (2015) is imperative in establishing and advancing a more effective market stance and approach - thus advancing a more effective competitive position in the market.

Studies (Adnan, 2015; Beal, 2000; Anotomic \& Hirsrich, 2001; Wambua \& Omondi, 2016) which have expressed interest in organizational competitiveness have identified the imperatives of learning in knowledge development and the drive for improved competitiveness. Yet still, organizational learning is only the first step towards building formidable and highly competitive organizations. Zhao, Flynn and Roth (2006) argued that to stand out within the context of today's market, there is the need for organizations to (a) learn and understand the unique features and attributes that define their environment, (b) identify their own internal capacities and strengths, and (c) effectively align and adjust their structures, systems and functions to match and address the changes in their environment. Toivonen and Viitanen (2016) noted that strategic sensitivity is as such a two-way process that starts from the environment, matching the features of the organization with the gaps in the environment -implying considerations of workers skills, technology and organizational competence as being a major concern of competitiveness.

This paper empirically investigated the relationship between strategic sensitivity and organizational competitiveness of deposit money banks in Rivers State. The paper in this way extends focus from the organizational learning stage to the strategic sensitivity stage. By this, the paper advances interest not only in the development and dynamic change apparent in the environment but also in the need for addressing the emerging change demands of the environment through the adapting and upgrading of organizational capacities and technologies. The paper is justified on the basis that it advances knowledge on the need for organizational change and competitiveness through both environmental assessment and selfevaluation; a process through which capacities are identified and form the primary basis for strategies and decisions. Based on foregoing, the objectives of this paper are to:

i. Determine the relationship between strategic sensitivity and service quality

ii. Examine the relationship between strategic sensitivity and delivery reliability

iii. Investigate the relationship between strategic sensitivity and innovativeness

\section{Research Questions}

The related questions which address the above issues are stated as follows:

i. What is the relationship between strategic sensitivity and service quality?

ii. What is the relationship between strategic sensitivity and delivery reliability?

iii. What is the relationship between strategic sensitivity and innovativeness? 


\section{Literature Review}

\section{The theory of Dynamic Capabilities}

The theory of dynamic capabilities advances a position on the need for organizations to consistently align their resources and capacities in line with the changes and evolving features of their environment. Panos (2013) described dynamic capabilities as the organizations fluidity in terms of knowledge and competence, and its ability to match such with the requirements and gaps of apparent in its environment. The theory provides a basis for understanding the interaction between strategic sensitivity and organizational competitiveness in the sense that it anchors the organizations capacity development on its learning and understanding of its environment. Thus, the competitiveness of the organization builds on this ability to effectively address and satisfy latent satisfaction gaps within its context through such learning. Chang, Lin, Yang and Sheu (2003) argued that the dynamic capabilities theory approaches the concept of change and development from a learning perspective, which according to him, emphasizes on organizations identification of key factors that offer them opportunities for relevance and innovation.

\section{Strategic Sensitivity}

Strategic sensitivity describes an organization'sscanning ability and knowledge development about its context, the internal assessment of its capacities and its alignment of functions and behaviour in a manner that advances it towards its goals and objectives. Pulaj \& Pulaj (2015) opined that strategic sensitivity can be futuristic as well as focused on the present functions of the organization. Primarily, it is concerned with planning the best course of action based on learning and the predictions of the future - hence, its concerns are based on addressing the uncertainties of the environment. Yarmohammadian, Alavi, Ahmadi, Fatemi and Moghadasi (2016) argued that one of the ways organizations can stay ahead and sustain their effectiveness is by building capacities that are futuristic in nature; thus availing trend setting services that in turn define the market. Zhao et al (2006) reiterated that strategic sensitivity advances and necessitates particular work and behaviour forms that seek to condition the organization for its current market while at the same time preparing it for a future based on its forecasts.

\section{Organizational competitiveness}

Competitiveness describes the extent to which the organization is aggressive in driving for its own success and goals (Jiang et al, 2018). Organizational competitiveness is considered unavoidable where organizations have to advance their service features to draw in customers alongside other organizations with similar goals. That is to say, markets which have organizations vying for the attention and interest of shared customers tend to engage in competition or perceive themselves as competitors. Jacobs, Vickery and Droge (2007) opined that competitiveness ensures the relevance and survival of the organization, and within highly populated markets, requires that organizations not only advance innovations that address existing gaps, but also adopt features and structures that are engaging. Competitiveness is considered as a relative factor and as earlier noted, is more severe in some contexts than others. Lee and Walsh (2016) affirmed that service industries are some of the most competitive; this is reflected in their advancing of technologies and processes that in most cases can be disruptive and unsettling. 


\section{Strategic Sensitivity and Organizational Competitiveness}

Jiang et al (2007) opined that organizations are units of their environment. Their environment defines their features and also impacts on their choices and decisions. In this way, learning enables the organization stay informed and ahead of the competition within its environment. Organizations with consistent research and development plans are considered effective in discerning the trends of their markets. This is according to Jiang et al (2015) imperative for strengthening organizational policies or adjusting such in line with expected change outcomes. This is reiterated by Hitt et al (2016) who observed that the scanning of the environment and the anchoring of internal strengths and capacities on observed gaps within the context of the environment are key to ensuring organizational competitiveness; with outcomes such as service quality, innovativeness and delivery reliability.

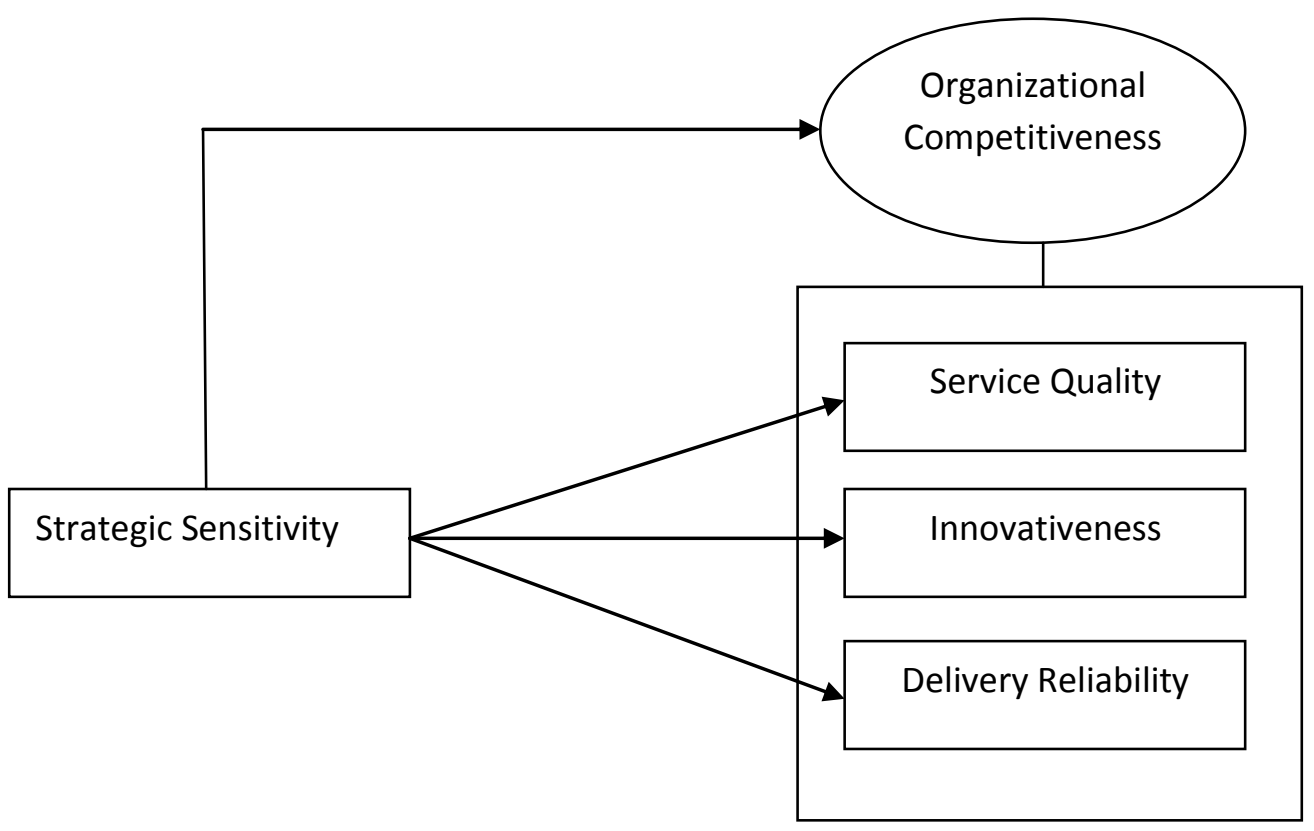

Figure 1: Operationalized framework for strategic sensitivity and organizational competitiveness

Strategic sensitivity and service quality: Studies on service quality often emphasize on established benchmarks and criteria that advance the organizations brand above others. Service quality as Jian and Morenao (2015) argued is based on a good understanding and knowledge of the context, and the organizations role in addressing the gaps in that context. It is primarily premised on the organizations development of solutions drawing from its learning experiences and capacity to predict future outcomes. Nonetheless, there is a lacking of supportive evidence specifying the nature of the relationship between strategic sensitivity and service quality. Thus it is hypothesized as follows:

$\mathrm{H}_{\mathrm{O} 1}$ : There is no significant relationship between strategic sensitivity and service quality of deposit money banks in Rivers State

Strategic sensitivity and innovativeness: Innovativeness according to Jian and Moreno (2015) describes a condition of change and creative capacity which enables product and service offerings that match latent satisfaction gaps of the customers. It is as such apparent that knowledge has to be developed in understanding not only the customer needs and gaps in the context or market, but also on areas that reflect overriding cultural and social values 
(Adnan, 2015). There is however a lacuna of studies which has adequately addressed the influence of strategic sensitivity on innovativeness; hence it is hypothesized as follows:

$\mathrm{H}_{\mathrm{O} 2}$ : There is no significant relationship between strategic sensitivity and innovativeness of deposit money banks in Rivers State

Strategic sensitivity and delivery reliability: The concept of delivery reliability builds primarily on brand consistency overtime and in their capacity to meet and match customer's needs and expectations. Jian and Moreno (2015) argued that one key facet and attribute of resilience and reliability is situation awareness based on the organizations active learning and interaction with stakeholders within the context of interest. Hitt et al (2016) corroborates this observation in stating that organizations are fused with various actors within and outside their workplace that make up its stakeholders. Effective dialogue and correspondence with these parties enables their health, harmony and capacity to meet up with market demands. Yet there is hardly any substantial empirical support for this position, hence it is hypothesized as follows:

$\mathrm{H}_{\mathrm{O} 3}$ : There is no significant relationship between strategic sensitivity and delivery reliability of deposit money banks in Rivers State

\section{Methodology}

The research design adopted for this study is the cross sectional design. The accessible population for the study is 266 senior staff of 18 deposit money banks in Rivers State. Given the size (where $\mathrm{n}<500$ ) of the population, the entire 266 staff identified were adopted in the investigation, thus making the investigation a census. Data for the investigation was also generated using the questionnaire instrument which was personally administered to the target deposit money banks within the state. Instrumentation for the variables was based on existing studies where the items for strategic sensitivity were sourced from Pulaj and Pulaj (2015), and the items for organizational competitiveness were also sourced from Jian and Moreno (2015). A total of 5 items were utilized as properties in assessing the features of strategic sensitivity, while organizational competitiveness, was assessed by drawing on the properties of its measures - with service quality having 5 items, delivery reliability utilizing 5 items, and then innovativeness also drawing on 5 items; thus a total of 15 items for organizational competitiveness. The Cronbach alpha test was utilized in assessing the reliability for the instruments of the study.

\section{Data Analysis and Report}

This section of the paper, presented the result on the distribution for the variables and the test on their relationships. While a total of 266 questionnaire copies were distributed, only 221 copies were successfully retrieved from the field, cleaned and considered suitable for inclusion in the study. The data is presented in three sections - (a) the demographic data distributions (b) the univariate data analysis, and (c) the test for the hypotheses. 


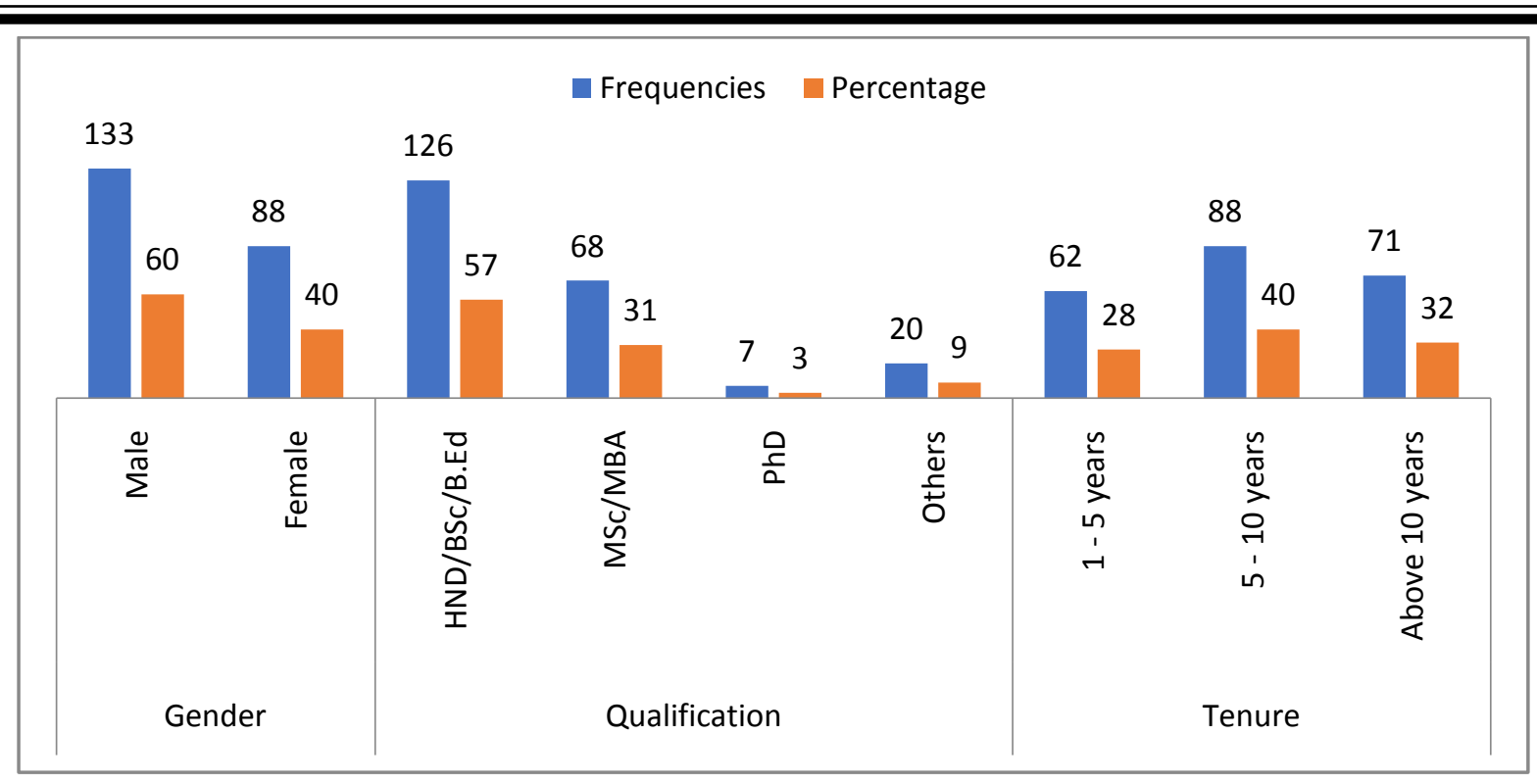

Figure 2: The demographic data distributions

It is observed that for the gender categorization, the male respondents have a higher frequency thantheir female counterparts where the male account for a frequency distribution of $133(60 \%)$ and the female account for a frequency distribution of $88(40 \%)$. Similarly, for the qualification categorization, respondents with HND/BSc./B.Ed are observed to have a more dominant frequency distribution at 126(57\%), followed by the distribution for respondents with MSc/MBA with a frequency of $68(31 \%)$, next is the frequency for $\mathrm{PhD}$ with $7(3 \%)$ and finally the distribution for others with $20(9 \%)$. In the third category - tenure with the organization, a more dominant group of respondents have frequencies for $5-10$ years at $88(40 \%)$, followed by the category for $1-5$ years with a frequency of $62(28 \%)$, and with the lowest at $71(32 \%)$.

\section{Univariate Data Analysis}

Table 1: Descriptive for variables of the study

\begin{tabular}{|l|r|r|r|r|r|r|r|}
\hline & \multicolumn{1}{|c|}{$\mathrm{N}$} & \multicolumn{1}{c|}{ Mean } & $\begin{array}{c}\text { Std. } \\
\text { Deviation }\end{array}$ & \multicolumn{2}{|c|}{ Skewness } & \multicolumn{2}{|c|}{ Kurtosis } \\
\cline { 2 - 8 } & Statistic & Statistic & Statistic & Statistic & $\begin{array}{c}\text { Std. } \\
\text { Error }\end{array}$ & Statistic & $\begin{array}{c}\text { Std. } \\
\text { Error }\end{array}$ \\
\hline Strategic Sensitivity & 221 & 2.7511 & .50767 & .759 & .164 & 4.127 & .326 \\
Innovativeness & 221 & 2.6846 & .49020 & .145 & .164 & 2.563 & .326 \\
Service Quality & 221 & 2.2482 & .52795 & -1.377 & .164 & .727 & .326 \\
Delivery Reliability & 221 & 2.7033 & .52469 & .628 & .164 & 3.281 & .326 \\
Valid N (listwise) & 221 & & & & & & \\
\hline
\end{tabular}

Source: Survey Data, 2021

The univariate data analysis for the distribution for the variables demonstrates evident support for the distribution for the variables. The result indicates that while all variables are noted to be substantially reflected, strategic sensitivity is observed to have the highest distribution; while service quality was observed to have the lowest distribution. The results 
Journal DOI: www.doi.org/10.46654/RJMP

Article DOI: $w$ ww.doi.org/10.46654/RJMP.1225

suggest evidence of the variables - implying that they substantially characterize the deposit money banks of interest to this investigation.

\section{Test for Hypotheses}

Table 2: The relationship between strategic sensitivity and organizational competitiveness

\begin{tabular}{|lll|r|r|r|r|}
\hline & & Sensitive & Innovative & Service & Delivery \\
\hline & \multirow{4}{*}{ Sensitive } & Correlation Coefficient & 1.000 & $.581^{* *}$ & $.160^{* *}$ & $.844^{* *}$ \\
& & Sig. (2-tailed) & .017 & .000 & .017 & .000 \\
& $\mathrm{~N}$ & 221 & 221 & 221 & 221 \\
& & Correlation Coefficient & $.581^{* *}$ & 1.000 & $.419^{* *}$ & $.750^{* *}$ \\
Spearman's & & .000 &. & .000 & .000 \\
rho & & 221 & 221 & 221 & 221 \\
& & $\mathrm{~N}$ & $.160^{*}$ & $.419^{* *}$ & 1.000 & $.233^{* *}$ \\
& Service & Correlation Coefficient & .017 & .000 &. & .000 \\
& & $\mathrm{~N}$ & 221 & 221 & 221 & 221 \\
& & Corg. (2-tailed) & $.844^{* *}$ & $.750^{* *}$ & $.233^{* * *}$ & 1.000 \\
& & .000 & .000 & .000 &. \\
& \multirow{2}{*}{ Delivery } & Sig. (2-tailed) & 221 & 221 & 221 & 221 \\
\hline
\end{tabular}

Source: Survey Data, 2021

The test for the relationship between strategic sensitivity and the measures of organizational competitiveness - innovativeness, service quality and delivery reliability, are all revealed to be significant. Results indicate that at a rho $=0.581$ and $\mathrm{P}=0.000$; strategic sensitivity significantly contributes towards innovativeness; at a rho $=0.160$ and a $\mathrm{P}=0.017$, strategic sensitivity significantly enhances service quality; and at a rho $=0.844$ and a $\mathrm{P}=0.000$; strategic sensitivity significantly influences delivery reliability. On this basis, all previously stated hypotheses are rejected and based on the evidence, restated as:

i. There is a significant relationship between strategic sensitivity and innovativeness

ii. There is a significant relationship between strategic sensitivity and service quality

iii. There is a significant relationship between strategic sensitivity and delivery reliability

\section{Discussion of the Findings}

The findings on the relationship between strategic sensitivity and organizational competitiveness indicate that the relationship is significant. This draws on the impact of strategic sensitivity on measures such as innovativeness, service quality and delivery reliability. The evidence suggests that organizations that understand and are sensitive to the facts and based on such understanding or sensitivity are able to develop service forms that customers want and try to increase their satisfaction have a higher tendency for success and enhanced competitiveness (Jian \& Moreno, 2015; Beal, 2000; Pulaj \& Pulaj, 2015). As such managers must have intelligent assumptions and adopt sensitive measures with regards to learning about and predicting future behaviours of customers, competitors and costs (Chang et al, 2003). In this vein, organizations can benefit substantially from their sensitivity to changes in their environment and also from the changing market opportunities where the benefits can be long or short-term (Beal, 2000). 
This study affirms that strategic sensitivity provides the ability to predict customer's needs and the movement of competitors. Therefore, strategic sensitivity enables a company to be more sensitive to the taste and preferences of customer (Toivonen \& Viitanen, 2016). Close relationships with customer enable the company to search for information on customer's preferences and needs and hence, it will be responsive. The insight gained by strong relationships with customers is used to increase operational effectiveness and cost efficiency, because members of organization agree on the vision of the company and can take effective measures (Zhao et al, 2006).

\section{Conclusion}

The evidence on the relationship between strategic sensitivity and the measures of organizational innovativeness, advance support for the imperatives of learning, research and planning for improved organizational decisions and functionality. The results from the study further validate the dynamic capabilities theory in affirming to the impact of strategic sensitivity on outcomes such as service quality, innovativeness and delivery reliability. In view of the positive outcome, it is concluded that strategic sensitivity based on its emphasis on learning and knowledge development, promotes and enhances outcomes of service quality, innovativeness and delivery reliability. 


\section{References}

Adnan, H. (2015): Effect of Organizational Culture, Organizational Commitment to Performance: Study in Hospital Of District South Konawe of Southeast Sulawesi, The International Journal of Engineering and Science, 4 (5), 33-41.

Antoncic, B. and Hisrich, R.D. (2001). Intrapreneurship: Construct refinement and crosscultural validation, Journal of Business Venturing, 16, 495-527

Beal, R.B. (2000): Competing Effectively; Environmental Scanning, Competitive Strategy, and Organizational Performance in Small Manufacturing Firms, Journal of Small Business Management, Vol. 38, (I), pp. 27-47.

Chang, S.-C., Lin, N.-P., Yang, C.-L. and Sheu, C. (2003) Quality dimensions, capabilities and business strategy: An empirical study in high-tech industry. Total Quality Management, 14(4), 407-421.

Hitt, M., Ieland,R., Hoskisson, R. (2016). Strategic Management: Concepts and Cases: Competitiveness and Globalization, 12th, Cengage Learning, USA.

Jacobs, M., Vickery, S., Droge, C., 2007. The effects of product modularity on competitive performance: Do integration strategies mediate the relationship? International Journal of Operations and Production Management 27 (10), 1046-1068.

Jain, A.K. and Moreno, A. (2015), "Organizational learning, knowledge management practices and firm's performance: an empirical study of a heavy engineering firm in India", The Learning Organization, Vol. 22 No. 1, pp. 14-39.

Jiang, W., Chai, H., Shao, J. and Feng, T. (2018), "Green entrepreneurial orientation for enhancing firm performance: a dynamic capability perspective", Journal of Cleaner Production, Vol. 198, pp. 1311-1323

Lee, Y.-N. and Walsh, J.P. (2016), "Inventing while you work: knowledge, non-RandD learning and innovation", Research Policy, Vol. 45 No. 1, pp. 345-359.

Panos, C. (2013). The failure of foresight in crisis management: A secondary analysis of the Mari disaster, Technological Forecasting \& Social Change, 80 (9): 1657-1673.

Pulaj, E., Pulaj, I. (2015). The effects of strategic environmental analysis on organizational performance, International Conference on Management, Business and Economics, Kosova, Albania

Toivonen, S., Viitanen, K. (2016). Environmental scanning and futures wheels as tools to analyze the possible future themes of the commercial real estate market, Land Use Policy, 52: 51-61

Wambua, j., Omondi, M. (2016). Factors influencing the environmental scanning of organizations in manufacturing sector: a case study of kenya breweries limited, The strategic journal of business and change management, 3 (2): 233-253.

Yarmohammadian, MH., Alavi, A., Ahmadi, F., Fatemi, M., Moghadasi, M. (2016). An investigation of the status of preparedness and crisis management restrictions in hospitals of Isfahan University of Medical Sciences. Int J Health Syst Disaster Manage, 4:58-62. 
Journal DOI: $\underline{\text { www.doi.org/10.46654/RJMP }}$

Vol. 1, Issue 2 (February, 2021) | www.ijaar.org

Article DOI: www.doi.org/10.46654/RJMP.1225

Zhao, X., Flynn, B.B., Roth, A.V., 2006. Decision sciences research in China: A critical review and research agenda-foundations and overview. Decision Sciences 37 (4), 451496. 